\title{
Eventos estressores em crianças e adolescentes em situação de vulnerabilidade social de Porto Alegre
}

\author{
Stressing events in socially vulnerable children and adolescents \\ in Porto Alegre
}

Michele Poletto ${ }^{1}$

Sílvia Helena Koller ${ }^{1}$

Débora Dalbosco Dell'Aglio ${ }^{1}$

${ }^{1}$ Instituto de Psicologia,

UniversidadeFederal do

Rio Grande do Sul. Rua

Ramiro Barcelos 2600/104,

Santana. 90035-003 Porto

Alegre RS.

michelepolettopsi@gmail.com
Abstract This paper investigated theoccurrenceand impact of stressing events for 297 low- income children/adolescents (both sexes; 7-16 years, $M=11.22$; $\mathrm{SD}=2.13$ ) in the city of Porto Alegre. Group 1 (G1) consisted of 142 participants (living with their families) and Group 2 (G2) of 155 institutionalized individuals. All were individually interviewed and answered the Stressing Events Inventory for Children/ Adolescents. The most frequent stressing events for the sample were: follow orders given by the parents $(85.2 \%)$; quarrels with friends $(72.9 \%)$; death of relatives $(71.8 \%)$; failure at school $(69.2 \%)$; and rivalry of siblings ( $68 \%)$. Student's t-test revealed significant difference between groups $(p<0,001)$ regarding the occurrence of stressing events, $G 2$ presented higher scores ( $M=26.79 ; S D=8.67)$ than $\mathrm{Gl}(\mathrm{M}=19.16$; $\mathrm{SD}=9.37)$. The events that caused the greatest impact upon the studied group were: death of parents and friends, rape, rejection by relatives and violence. There was no significant difference between sexes $(p>0.05)$. The high frequency and strong impact of stressing events reveal the situation of social and familiar vulnerability, presence of violence and lack of resources in the whole group.

Key words Stressing events, Children, Adolescents, Impact
Resumo 0 presente artigo investigou a ocorrência eo impacto de eventos estressores para 297 crianças/ adolescentes em situação de vulnerabilidade social de Porto Alegre (ambos os sexos; 7-16 anos, $\mathrm{M}=$ 11,22; SD =2,13). 0 grupo 1 (G1) consistiu em 142 participantes, que viviam com suas famílias e o grupo 2 (G2), em 155 institucionalizados. Todos foram entrevistados e responderam individualmente ao Inventário de Eventos Estressores na Infância/Adolescência. Os eventos estressores mais freqüentes para amostra total foram: cumprir ordens dos pais $(85,2 \%)$; discussão com amigos (72,9\%); morte de familiares (71,8\%); reprovação escolar $(69,2 \%)$; e brigas com irmãos (68\%). U m testet de Student re velou diferença significativa entre G1 eG2 $(p<0,001)$ na variável ocorrência de eventos estressores, sendo queG 2 apresentou médiasmaisaltas ( $M=26,79 ;$ SD $=8,67)$ que $\mathrm{G} 1(\mathrm{M}=19,16 ; \mathrm{SD}=9,37)$. Os eventos que tiveram maior impacto na amostra estudada foram: morte dos pais e amigos, estupro, rejeição de familiares e sofrer violência. $N$ ão houve diferença significativa entre meninos e meninas $(p>0,05)$. A alta ocorrência e impacto de eventos estressores expõem a situação de vulnerabilidadesocial efamiliar, presença de violência e privação de recursos em ambos os grupos.

Palavras-chave Eventos estressores, Criança, Adolescente, Impacto 


\section{Introdução}

O objetivo deste estudo foi avaliar a ocorrência de eventos estressores e seu impacto na vida de crianças e adolescentes em situação de vulnerabilidade social. Alguns eventos de vida podem ser estressantes, como, por exemplo: mudanças na composição familiar, transições na escola e com pares, mas em geral configuram-se como acontecimentos esperados no ciclo vital humano. De qualquer forma, estes eventos podem provocar conseqüências adversas à saúde e ao bem-estar social e psicológico de crianças e adolescentes. Segundo M asten eGarmezy ${ }^{1}$, eventos estressores são definidos como ocorrências de vida que alteram o ambiente e provocam uma tensão que interfere nas respostas emitidas pelos indivíduos.

0 foco em eventos estressores no estudo do desenvolvimento infantil tem-secentrado, primordialmente, em temas como divórcio dos pais², abuso sexual/físico contra a criança e o adolescente ${ }^{3,4}$, pobreza eempobrecimento ${ }^{5,6}$, guerras e outras formas de trauma ${ }^{7}$. Tradicionalmente, estes estressores eram concebidos de maneira estática, ou seja, na presença de qualquer um deles já eram previstas conseqüências indesejáveis. No entanto, deacordo com Koller e De Antoni ${ }^{8}$, a relação das pessoas com eventos estressores passa por distintos graus de ocorrência, intensidade, freqüência, duração e severidade. 0 impacto dos eventos estressores é determinado pela forma como eles ocorrem, mas também como são percebidos. Estudos realizados com crianças e adolescentes que vivenciam inúmeros eventos estressores, como na guerra, afirmam que as reações ao estresse dependem da idade, do gênero, da fase desenvolvimental e das habilidades cognitivas e emocionais da criança ou do adolescente $^{9,10}$. Algumas crianças são capazes de enfrentar e superar os eventos estressores com mais rapidez, enquanto outras experienciam efeitos negativos mais severos e de longa duração ${ }^{11}$. Portanto, dianteda variabilidade de reações ao estresseeconsiderando os aspectos que o envolvem, deve haver cautela ao classificá-lo como um fator de risco que podegerar sintomas psicopatológicos ${ }^{12}$. As demais influências e condições sociais, pessoais e emocionais daquele que sofre o estresse devem ser avaliadas ${ }^{13-15}$. Um evento negativo de vida poderá, no entanto, ser considerado como fator derisco quando sua presença aumentar a probabilidade de provocar problemas físicos, sociais ou emocionais ${ }^{14}$. Assim, uma criança será considerada em situação de risco quando estiver exposta a eventos de vida estressores, que possam comprometer seu desenvolvimento ${ }^{16}$.
Risco pode ser definido como processo, conformesalientou Rutter ${ }^{17}$, pois seusingredientes não se situam nele mesmo de forma estática. Fatores de risco são processos ativos, expressos com dinamicidade nos contextos, cultura, história e características pessoais, que juntos ou isolados provocam resultados disfuncionais. Pobreza, empobrecimento, baixa escolaridade, ocupação de baixo status dos pais/cuidadores, ausência de rede de apoio social e afetiva são apontados como condições negativas no desenvolvimento de crianças e jovens, embora não determinantes a priori. No entanto, quando associados à percepção de precariedade, ausência de possibilidades e esperança em superar desafios e barreiras, podem dificultar 0 acionamento de processos de resiliência e agravar a vulnerabilidade ${ }^{18}$.

Em um estudo sobre a ocorrência e o impacto de eventos de vida estressores em adolescentes de Porto Alegre, Kristensen, Leon, D'Incao eD ell'Aglio ${ }^{19}$ utilizaram uma adaptação do Inventário de Eventos Estressores na Adolescência (IEEA) ${ }^{20}$. Alta ocorrência de problemas no contexto escolar, nas relações com pares e com a família foi identificada. Apontaram, também, que eventos, como situações de privação e violência, embora menos freqüentes, eram considerados de forte impacto pelos adolescentes. Dianteda diversidadee da presença inevitável de eventos estressores ao longo do ciclo vital, torna-se importante conhecer quais são os eventos estressores que ocorrem nas vidas de crianças e adolescentes, em diferentes contextos de desenvolvimento. Além da ocorrência, o impacto detaiseventos deve ser avaliado segundo o ponto de vista das próprias crianças e adolescentes.

\section{Método}

\section{Participantes}

A amostra foi composta por 297 crianças e adolescentes em situação de vulnerabilidade social com idades entre sete e dezesseis anos ( $M=11,22$ anos; SD $=2,13$ ), sendo 155 do sexo masculino $(52,2 \%)$ e 142 do sexo feminino (47,8\%). Todos freqüentavam da segunda a oitava série do ensino fundamental de escolas públicas de Porto Alegre em 2006. D ois grupos foram constituídos com base no contexto de desenvolvimento. 0 grupo 1 (G1) foi composto por 142 crianças que viviam com sua família (47,8\%), com idademédia de 11,27 (SD $=2,24$ ), sendo 66 do sexo feminino e 76 do masculino. 0 grupo 2 (G2) foi composto por 155 que moravam em instituições de abrigo (52,2\%), com 
idademédia de 11,17 ( $S D=2,03$ ), sendo 76 do sexo feminino e 79 do masculino. Foram excluídos da amostra participantes institucionalizados que não freqüentavam a escola ecrianças eadolescentes que não compreendiam os instrumentos. Não foi utilizado nenhum instrumento para avaliação cognitiva das crianças e adolescentes como critério para compor a amostra, mas os entrevistadores verificavam se os participantes entendiam o que era solicitado e se apresentavam condições de responder aos instrumentos. N enhum participantefoi excluído por não entender a entrevista ou o inventário de eventos estressores.

Os participantes que moravam com a família foram selecionados em duas escolas estaduais que concordaram em participar do estudo. Estas escolas foram selecionadas por conveniência, considerando-se a localização em bairro de nível socioeconômico desfavorecido (baixas condições de habitação e acesso a serviços, com carência de áreas de lazer seguras e limpas e presença de violência), caracterizando vulnerabilidade social. Para selecionar os participantes do grupo 1 , foi realizado um sortei o nas turmas de segunda, quarta e sexta séries do ensino fundamental. Os sorteados foram convidados a participar e todos os que concordaram foram incluídos.

A amostra decriançase adolescentes institucionalizados (G2) foi selecionada a partir de uma lista de abrigos fornecida pela coordenação municipal e estadual dos abrigos. Desta listagem, foram selecionados nove abrigos de proteção governamentais enão-governamentais da GrandePorto Alegre. Participaram todos os institucionalizados quefreqüentavam escola, com idades entre setee dezesseis anos e que aceitaram ser participantes do estudo até se chegar ao número de participantes esperado. As unidades de abrigos estaduais acolhiam aproximadamente treze crianças e/ou adolescentes em residências de pequeno porte, sob os cuidados de monitores. As crianças e adolescentes utilizavam recursos da comunidade próxima aos abrigos, como escola, centros de lazer, praças e atendimento de saúde. 0 abrigo municipal, que foi contexto para coleta de dados, apresentava médio porte, atendendo cerca de trinta crianças e/ou adolescentes (dez em cada residência), assistidos por educadores. Uma das instituições não-governamentais ou filantrópicas visitada era composta por três casas, com dez crianças de até catorze anos, vivendo sob o sistema de casa-lar, e cuidados por mães e pais sociais. A outra instituição atendia vinte meninas até dezoito anos. Ascrianças eadolescentes institucionalizados foram considerados em situação de vulnerabilidade social por estarem em situação que demanda proteção especial e por terem vivenciado rupturas de laços familiares e eventos adversos antes do período deinstitucional ização.

\section{Instrumentos}

Foi utilizada uma entrevista estruturada para investigar dados biosociodemográficos (idade, sexo, entre outros) e o Inventário de Eventos Estressores na I nfância e na Adolescência, adaptado do Inventário de Eventos Estressores na Adolescência (IEEA) ${ }^{20}$. 0 inventário original era composto por 64 itens, dos quais se mantiveram sessenta no instrumento adaptado. Foram retirados itens aplicáveis apenas aos adolescentes (perder 0 emprego, assumir o sustento da família, ficar grávida/a namorada ficar grávida, fazer aborto/a namorada fazer aborto). 0 instrumento adaptado identifica os eventos estressores ocorridos com os participantes e qual a percepção de impacto sobre cadaum deles. A presença/ausência de cada evento foi marcada por sim (1)/não (0), respectivamente. Em caso de ocorrência de um evento, os participantes deveriam indicar o quanto esse foi percebido como estressante, em uma escala de 1 a 5 ( 1 indica nada estressante; 2 um pouco estressante; 3 mais ou menos estressante; 4 muito estressante, e 5 totalmente estressante). Ao final, foi somado 0 total de eventos presentes (ocorrência) e observado o impacto percebido para cada um destes eventos na trajetória de vida de cada participante.

A fim de realizar uma análise baseada nos tipos de eventos estressores, estes foram reunidos em três grupos: família, escola e domínio pessoal. Os eventos relacionados ao grupo da família foram, por exemplo: "a família ter problemas com a polícia" e "um dos pais casar novamente". Com relação à escola, foram usados itens como: "tirar notas baixas na escola", "ser suspenso da escola", "ser xingado(a)" ou "ameaçado(a) verbalmente por professores(as)". No domínio pessoal, os eventos envolviam aspectos individuais, tais como: "ter dificuldades em fazer amizades", "ter que viver em abrigo", "sofrer humilhação" ou "ser desvalorizado(a)". A categorização dos eventos por grupo foi realizada por três juízesque, individualmente, agruparam os itens do inventário. As categorizações dosjuízes foram comparadas entresi ehouve $100 \%$ de consenso nos grupos criados e na determinação de quais itens comporiam cada um deles. Foram somados os escores de cada grupo e criado um escore para cada um, a saber: família ( 23 itens), escola ( 9 itens) e domínio pessoal ( 28 itens) de cada participante. 


\section{Procedimentos}

O presente estudo foi aprovado pelo Comitê deÉtica da UniversidadeFederal do Rio Grandedo Sul. Os procedimentos utilizados obedeceram aos Critérios da Ética na Pesquisa com Seres Humanos, conforme a Resolução no 196/96, do ConseIho Nacional de Saúde. Foi solicitada a concordância das instituições e escolas para real ização da pesquisa, assim como o consentimento dos pais/ responsáveis e dos participantes. Os responsáveis legais pela guarda das crianças e adolescentes da instituição assinaram o termo de concordância das mesmas e consentiram que os mesmos participassem do estudo. Pais/responsáveis, e participantes maiores de doze anos assinaram um termo de consentimento livre e esclarecido, após serem informados sobre a natureza do estudo e do uso dos dados coletados.

A coleta de dados foi realizada em 2006 nas escolas e nas instituições em encontros com duração entreuma euma hora emeia, com cada participante. Os entrevistadores eram estudantes de graduação em psicologia e psicólogos voluntários treinados em aspectos teóricos, metodológicos e éticos.

\section{Análise estatística}

A tabulação e análise dos dados foi realizada com o PacoteEstatístico para Ciências Sociais, versão 12 paraW indows (SPSS 12.0). Inicialmentesão apresentadas as análises estatísticas descritivas de freqüências e percentagens dos dados biosociodemográficos dos participantes, relativos às suas famílias eescolas. Foram realizadas análises da ocorrência e do impacto dos eventos estressores, com os testes $t$ de Student e qui-quadrado para verificação de diferenças entre grupos com relação a variáveis sexo e contexto. Foi realizada uma análise multivariada (general linear model) para verificar interação dos três grupos (família, escola e domínio pessoal) nasvariáveisindependentes (sexo e contexto de desenvolvimento). Nas análises, foi adotado um $p<0,05$ como nível de significância crítico.

\section{Resultados}

O Inventário de Eventos Estressores na Infância e na Adolescência verificou a ocorrência média de 22,96 eventos $(S D=9,79)$ em um total de 60 , para as crianças e adolescentes entrevistados $(\mathrm{N}=269)$. Os eventos estressores mais citados foram: "ter que obedecer às ordens de seus pais" ( $85,2 \%)$, "discutir com amigos(as)" (72,9\%), "morte de outro familiar" (71,8\%), "rodar de ano na escola" (69,2\%), "ter brigas com irmãos(ãs)" (68\%) e "mudar de casa ou de cidade" (65,8\%). No entanto, ao comparar G1 e G2, um teste t de Student mostrou diferença significativa na média de ocorrência de eventos estressores $[t(1,267)=6,92 ; p<0,001]$. As crianças de $G 2$, que moram em instituição, apresentaram médias maisaltas deeventos estressores ( $M=26,79$; $\mathrm{SD}=8,67$ ) que as que viviam com a família ( $\mathrm{G} 1, \mathrm{M}$ $=19,16 ;$ SD =9,37). A Tabela 1 apresenta os eventos estressores mais freqüentes por grupo. Um teste de qui-quadrado apontou associações significativas entre os eventos e o contexto. Os eventos "ter problemas com professores", "a família não ter dinheiro", "discutir com amigos(as)", "rodar de ano na escola", "mudar de colégio", "mudar de colégio", "ir para o conselho tutelar", "ter que viver em abrigo", "sofrer castigos e punições" e "separação dos pais" foram associados ao grupo da instituição, enquanto que "al guém da família perder o emprego" e"ter dificuldades em fazer amizades" foram associados ao grupo da família.

$\mathrm{N}$ ão foi encontrada diferença significativa por sexo (teste t de Student; $p>0,05$ ) em relação à mé dia de ocorrência dos eventos estressores ( $0^{\circ} \mathrm{M}=$ 22,$73 ; \mathrm{SD}=10,16$; e $\mathrm{M}=23,20 ; \mathrm{SD}=9,41$ ). $\mathrm{Na}$ Tabela 2, são observados os eventos estressores que apresentaram associação significativa com sexo através de um teste de qui-quadrado .

Para uma análise mais detal hada da ocorrência de eventos estressores, foram criados três grupos e calculado um escore padronizado, uma vez que os grupostêm número deitens diferentes: família(23), escola (9) e domínio pessoal (28). O somatório bruto da ocorrência dos eventos estressores de cada grupo foi dividido pelo número deitens pertencentes a ele. Estes valores foram submetidos a uma análise multivariada (GLM) , que não revelou interação $(p>0,05)$ dos três grupos (família, escola e domínio pessoal) nasvariáveis independentes (sexo e contexto de desenvolvimento).

Um testet de Student foi, então, realizado, para verificar a relação da variável ocorrência de eventos estressores nos grupos criados (família, escola, domínio pessoal, ver seção análise dos dados), comparando-os em relação aos sexos. A análise comparativa das médias do grupo família e domínio pessoal por sexo não revelou diferença significativa $(p>0,05)$. Foi encontrada diferença significativa em relação ao grupo escola $[t(1,285)=1,94$; $p<0,05)$ entre os sexos. Os meninos $(M=0,40$; $\mathrm{SD}=0,225$ ) tiveram média mais al ta na ocorrência de eventos estressores no grupo escola que as me$\operatorname{ninas}(M=0,35 ; S D=0,216)$. 
Tabela 1. Percentuais de ocorrência de eventos estressores em crianças/adolescentes por contextos de desenvolvimento (família, instituição).

\begin{tabular}{lccr}
\hline \multicolumn{1}{c}{ Eventos estressores } & $\begin{array}{c}\text { Instituição } \\
n=155(\%)\end{array}$ & $\begin{array}{c}\text { Família } \\
n=142(\%)\end{array}$ & $\begin{array}{c}\text { Total } \\
(\%)\end{array}$ \\
\hline Ter problemas com professores & $43,6^{*}$ & 31,7 & 37,8 \\
A família não ter dinheiro & $66,9^{* *}$ & 48,6 & 57,9 \\
Discutir com amigos(as) & $77,9^{*}$ & 67,6 & 72,9 \\
Rodar de ano na escola & $75,3^{*}$ & 62,7 & 69,2 \\
Alguém da família perder o emprego & 49 & $62,7 *$ & 55,7 \\
Mudar de colégio & $78,7 * * *$ & 43,7 & 61,6 \\
Mudar de casa ou de cidade & 70 & 61,3 & 65,8 \\
Ir para o conselho tutelar & $60,8^{* * *}$ & 11,3 & 36,6 \\
Ter que viver em abrigo & $98^{* * *}$ & 10,6 & 55,7 \\
Ter brigas com irmãos(ãs) & 72,5 & 63,4 & 68 \\
Ter que obedecer às ordens dos pais & 85,9 & 84,5 & 85,2 \\
Sofrer castigos e punições & $73,2^{* * *}$ & 40,1 & 57 \\
Ter dificuldades em fazer amizades & 60,1 & $76,1 * *$ & 32,1 \\
Separação dos pais & $61,2 * *$ & 45,8 & 53,6 \\
\hline
\end{tabular}

Nota: $* p<0,05 ; * * p<0,01 ; * * * p<0,001$

Tabela 2. Percentuais da ocorrência dos eventos estressores por sexo.

\begin{tabular}{lccc}
\hline \multicolumn{1}{c}{ Eventos estressores } & $\begin{array}{c}\text { Feminino } \\
n=142(\%)\end{array}$ & $\begin{array}{c}\text { Masculino } \\
n=155(\%)\end{array}$ & $\begin{array}{c}\text { Total } \\
(\%)\end{array}$ \\
\hline Ter problemas e dúvidas quanto às mudanças no corpo e aparência & $42,3^{*}$ & 28,9 & 35,4 \\
M orte de irmãos(ãs) & $34,0^{*}$ & 21,0 & 27,5 \\
Ter familiares doentes ou deficientes & $51,4^{*}$ & 38,0 & 44,5 \\
Ter problema com outros pela sua raça & $26,1^{* * *}$ & 11,3 & 18,5 \\
Ser tocado(a) sexualmente & $24,3^{*}$ & 12,7 & 18,3 \\
Ser suspenso(a) da escola & 3,5 & $21,3^{* * *}$ & 12,7 \\
Ter algum familiar que bebe muito & $60,7 * *$ & 45,3 & 52,8 \\
Ser assaltado(a) & 12,8 & $24,7 * *$ & 18,9 \\
Ser expulso(a) da escola & 4,3 & $10,7 *$ & 7,6 \\
Ser expulso(a) da sala de aula pela professora & 19,1 & $32,0 *$ & 35,8 \\
Sofrer acidente & 18,4 & $32,0 * *$ & 25,4 \\
\hline
\end{tabular}

Nota: ${ }^{*} p<0,05 ; * * p<0,01 ; * * * p<0,001$

Uma análise comparativa das médias da ocorrência de eventos estressores nos grupos criados (família, escola, domínio pessoal) por contexto de desenvolvimento (família, instituição), utilizando teste t de Student, apontou diferença significativa entre os contextos em relação ao grupo família $[\mathrm{t}(1,281)=4,09 ; \mathrm{p}<0,001)$. As crianças que vivem em instituições ( $G 2 ; M=0,45 ; S D=0,166)$ tiveram média mais alta de ocorrência de eventos estressores que $G 1(M=0,37 ; S D=0,166)$. Também foi encontrada diferença significativa através do teste $t$ de Student em relação ao grupo escola $[\mathrm{t}(1,287)=$ 3,$99 ; p<0,001$ ) entreas crianças quevivem em instituições ( $G 2 ; M=0,43 ; S D=0,223$ ) e as que moram com a família ( $G 1 ; M=0,32 ; S D=0,209)$. Ainda foi encontrada diferença significativa utilizando teste $t$ de Student em relação ao grupo domínio pessoal $[t(1,281)=9,24 ; p<0,001)$ entre os grupos ( $\mathrm{G} 1$ e G2), sendo que as crianças que vivem em instituições $(M=0,45 ; S D=0,165)$ tiveram média mais alta no grupo pessoal do que as de $\mathrm{Gl}$ ( $\mathrm{M}=$ 0,$26 ; S D=0,179$ ). Tais dados indicam que as crian- 
ças institucionalizadas (G2) tiveram mais eventos estressores relacionados à família, à escola e ao domínio pessoal que as crianças que moravam com as suas famílias ( $\mathrm{G} 1$ ).

\section{Impacto dos eventos estressores}

A análise do impacto dos eventos ocorridos (intensidade do estresse vivido/sentido) apontou: "morte dos pais" ( $M=4,21 ; S D=1,23)$, "ser estuprado" ( $M=4,14 ; S D=1,56)$, "ser rejeitado por familiares" ( $M=4,07 ; S D=1,88)$, "morte de amigos" $(M=4,06 ; S D=1,78)$, "ter sofrido algum tipo de violência" ( $M=4,03 ; S D=1,69)$ e"ser tocado sexualmente contra vontade" $(M=4,00 ; S D=1,13)$ como os mais estressantes para a amostra total.

Utilizando teste t de Student, foi encontrada diferença significativa por contexto de desenvolvimento (família, instituição), em relação ao impacto dos eventos estressores. $\mathrm{Na}$ Tabela 3 , estão apresentados os resultados do teste t de Student e as médias e desvios-padrão dos eventos que apresentaram diferença significativa por contexto de desenvolvimento. Constatou-se que, na maioria dos eventos, o impacto foi maior para as crianças que vivem com a família.

Apesar de não apresentarem diferença significativa entre os contextos, alguns eventos se mostraram altamente estressantes para todos participantes da amostra que os vivenciaram. Entre esses eventos estão: "não conhecer um dos pais", "ter dormido na rua", "ter crise nervosa", "sofrer humiIhação" ou "ser desvalorizado(a)", "sofrer agressão física ou ameaça de agressão por parte dos pais", "ter algum familiar que bebe muito", "ser rejeitado(a) pelos familiares", "ser assaltado(a)", "ser xingado(a) ou ameaçado(a) verbalmente por professores(as)", "separação dos pais", "ser expulso da escola" e "sofrer acidente". Os eventos classificados como totalmente estressantes, ou seja, que os participantes pontuaram 5, para ambos os sexos e contextos de desenvolvimento foram: "morte de um dos pais, irmãos(ãs) e familiares", "ser tocado(a) sexualmente contra a vontade", "ser impedido(a) de ver os pais", "ser expulso de casa", "envolver-se em brigas com agressão física", "ter sofrido algum tipo de violência" e "sofrer acidente". Estes eventos, em específico, não apresentaram diferença significativa entre os contextos de desenvolvimento G1 e G2 (testet de Student; $p>0,05$ ).

Foi encontrada diferença significativa por sexo, em relação ao impacto dos eventos estressores vivenciados. A Tabela 4 apresenta os eventos, os re sultados do testet deStudent e as médias e desviospadrão do impacto dos eventos estressores por sexo que apresentaram diferença significativa entre meninos e meninas. Constatou-se que, na maioria dos eventos, o impacto foi maior para as meninas.

\section{Discussão}

Inúmeros eventos estressores foram constatados como freqüentes na história dos participantes deste estudo. De um total de sessenta eventos estressores, cada criança informou ter vivenciado em média um terço do total destes eventos em sua vida. A amostra deste estudo apresentou, no entanto, variação nos tipos de eventos mais freqüentes e na avaliação do impacto atribuído aos eventos estres-

Tabela 3. M édias (desvios- padrão) do impacto dos eventos estressores em crianças/adolescentes por contexto de desenvolvimento (instituição, família).

\begin{tabular}{|c|c|c|c|c|c|c|}
\hline \multirow[t]{2}{*}{ Evento } & \multirow[t]{2}{*}{$\mathrm{n}$} & \multirow[t]{2}{*}{$t(g l)$} & \multicolumn{2}{|c|}{ Instituição } & \multicolumn{2}{|c|}{ Família } \\
\hline & & & M & SD & M & SD \\
\hline A família ter problemas com a polícia & 112 & $2,32(1,110)$ & $3,57 *$ & 1,44 & 2,96 & 1,26 \\
\hline Um dos pais ter filhos com outros parceiros & 154 & $4,57(1,152)$ & $2,97 * * *$ & 1,64 & 1,91 & 1,22 \\
\hline $\mathrm{N}$ ão ter amigos(as) & 105 & $2,22(1,103)$ & 2,97 & 1,23 & $3,57 *$ & 1,47 \\
\hline Ser levado(a) para a FASE ou algum abrigo & 161 & $2,50(1,159)$ & 2,87 & 1,69 & $3,91^{*}$ & 1,30 \\
\hline Ter que viver em abrigo & 163 & $3,11(1,161)$ & 2,49 & 1,60 & $3,56 * *$ & 1,26 \\
\hline Envolver-se em brigas com agressão física & 142 & $2,20(1,140)$ & 3,39 & 1,43 & $3,93 *$ & 1,37 \\
\hline Ser expulso(a) da sala de aula pela professora & 75 & $2,60(1,73)$ & 2,57 & 1,55 & $3,41^{*}$ & 1,24 \\
\hline
\end{tabular}

Nota: $* p<0,05 ; * * p<0,01 ; * * * p<0,001$ 
Tabela 4. M édias (desvios- padrão) do impacto dos eventos estressores por sexo.

\begin{tabular}{|c|c|c|c|c|c|c|}
\hline \multirow[t]{2}{*}{ Evento } & \multirow[t]{2}{*}{$\mathrm{n}$} & \multirow[t]{2}{*}{$t(g l)$} & \multicolumn{2}{|c|}{ Feminino } & \multicolumn{2}{|c|}{ Masculino } \\
\hline & & & M & SD & M & SD \\
\hline Ter problemas com professores & 110 & $3,00(1,108)$ & $3,49 * *$ & 1,48 & 2,69 & 1,24 \\
\hline Discutir com amigos(as) & 214 & $2,69(1,212)$ & $3,36 *$ & 1,32 & 2,89 & 1,24 \\
\hline Rodar de ano na escola & 202 & $2,10(1,200)$ & $3,50 *$ & 1,39 & 3,07 & 1,51 \\
\hline Ir para o consel ho tutelar & 107 & $1,98(1,105)$ & $3,56 *$ & 1,63 & 2,96 & 1,45 \\
\hline Não receber cuidado e atenção dos pais & 105 & $2,40(1,103)$ & $3,97 *$ & 1,32 & 3,30 & 1,51 \\
\hline Ter algum familiar que usa drogas & 129 & $2,03(1,127)$ & $4,00 *$ & 1,39 & 3,47 & 1,57 \\
\hline Ter doenças graves ou lesões sérias & 101 & $1,93(1,99)$ & $3,81 *$ & 1,50 & 3,22 & 1,50 \\
\hline Ter problemas com os outros pela sua raça & 54 & $2,00(1,52)$ & $3,65^{*}$ & 1,37 & 2,82 & 1,46 \\
\hline Tirar notas baixas na escola & 189 & $2,03(1,187)$ & $3,42 *$ & 1,43 & 3,00 & 1,38 \\
\hline Ficar pobre & 117 & $2,18(1,115)$ & $3,58^{*}$ & 1,48 & 2,98 & 1,47 \\
\hline Terminar o namoro & 91 & $2,81(1,79)$ & $3,61^{* *}$ & 1,46 & 2,72 & 1,52 \\
\hline Ser estuprado(a) & 22 & $2,26(1,20)$ & 3,71 & 1,85 & $4,88 *$ & 0,35 \\
\hline Morte de amigo(a) & 78 & $2,57(1,76)$ & 3,78 & 1,25 & $4,38^{*}$ & 0,75 \\
\hline
\end{tabular}

Nota: $* p<0,05 ; * * p<0,01$

sores. Contudo, ainda sob extrema adversidade, muitas vezes, serão de tais situações que gerarão possibilidades de enfrentamento e superação de dificuldades ${ }^{12,21}$. A forma como 0 evento estressor é percebido deve ser levada em conta, pois essa percepção pode atuar como moderadora do processo de enfrentamento da situação ${ }^{22}$. Além disso, também devem ser considerados outros fatores mediadores na vida destas crianças e adolescentes, tais como as características individuais e o suporte afetivo e social percebido nos seus contextos de desenvolvimento. Por isso, o estudo do impacto dos eventos estressores vividos pelos participantes deve ser levado em conta.

\section{Eventos estressores}

Os eventos estressores com maior ocorrência estão relacionados aos contextos escolar e familiar das crianças e adolescentes. De acordo com Bronfenbrenner ${ }^{23}$, são a escola e a família que constituem os principais microssistemas nos quais esta população estabelecerelações face-a-facee de reciprocidade ${ }^{23}$. Porém, as crianças e os adolescentes institucionalizados apresentaram maior número de eventos estressores. Este fato talvez se deva às vivências anteriores destas crianças e adolescentes à entrada na instituição, geralmente determinada por medida de proteção quando a família, por suas dificuldades e limitações, não é capaz de prover segurança, cuidado e carinho ${ }^{24}$.
0 evento estressor mais freqüente na amostra total estudada foi "ter que obedecer às ordens de seus pais". Este resultado tem uma forte relação com a fase do desenvolvimento que os participantes seencontram. Crianças eadolescentes mostramse, em geral, incomodados, quando são chamados a obedecer a ordens ou quando alguém aponta os limites a serem respeitados, e os pais/responsáveis em geral são aqueles que exercem esta função $0^{25} . \mathrm{Na}$ faixa etária investigada, inicia-se o processo de independização, contestação da autoridade e questionamento de regras, elementos necessários para o desenvolvimento da sua identidade eadequados ao seu nível de desenvolvimento cognitivo ${ }^{26}$.

A morte de familiares apareceu como evento estressor de al to impacto e, em geral, estava ligado a episódios de violência, como assassinatos e brigas e, também, a doenças, como aids. De acordo com Walker e colaboradores ${ }^{16}$, o número de crianças expostas à violência em países em desenvolvimento é amplo. Tal exposição aumenta os níveis de estresse pós-traumático, agressividade, proble mas de atenção e depressão. 0 efeito negativo da exposição à violência pode ser maior quando não há coesão familiar ou um dos cuidadores tem problemas emocionais. No entanto, experiências escolares positivas para tais crianças e orientação e suporte para suas famílias podem aumentar os níveis de competência sócio-emocional.

Os eventos "ter brigas com irmãos(ãs)" e "discutir com amigos(as)" foram freqüentes para as 
crianças deambos os contextos edemonstram que há dificuldades no relacionamento com pares. Crianças que vivem em instituição podem considerar o relacionamento com os amigos como se estes estivessem no lugar dos irmãos, devido à proximidade física e convivência. Para Dell'Aglio 27, 0 de sentendimento com pares e irmãos também foi um dos eventos mais freqüentes citados pelas crianças institucionalizadas. Em um estudo realizado por Finkelhor, Turner e 0 rmrod $^{28}$, com 2.030 crianças e adolescentes, foi observado que a violência entre irmãos, comparada à violência entre pares, mostrou-se com maior probabilidade de ocorrer como uma condição crônica. Ser vítima de violência de irmãos foi associado a sintomas que podem indicar efeitos traumáticos tanto em crianças como em adolescentes. No entanto, não são descartadas possibilidades de que outros fatores possam contribuir para a ocorrência de brigas e discussões entre os irmãos e pares, tais como temperamentos irritáveis e supervisão inadequada dos pais.

Brigas com irmãos ocorrem em ambos os contextos, indicando necessidade de obter maior atenção de profissionais da saúde e da educação. Todavia, as brigas com irmãos epares podem ser entendidas como acontecimentos presentes ao longo do desenvolvimento da vida de crianças e adolescentes, uma vez quefuncionam, igualmente, como um laboratório de experiências relacionais. É preciso verificar cada caso, pois o relacionamento entre pares e irmãos também é apontado como fator de proteçãa 29,30 . Com irmãos e pares, as crianças trocam, dividem, empurram, mantêm contatos físicos como expressões de afeto (carícias, beijos e abraços). Tais comportamentos e trocas revelam aspectos importantes na socialização e no desenvolvimento humano ${ }^{31}$.

Diante dos eventos estressores apresentados, parece que "ter que obedecer às ordens dos pais" e "brigar com irmãos" foram eventos freqüentes nos dois contextos investigados. Tais eventos podem estar relacionados às características das famílias (falta de manejos e supervisão inadequada dos cuidadores) como também das crianças estudadas (temperamento, agressividade, irritação) ${ }^{28}$ Além disso, é importante prestar atenção ao acúmulo de eventos estressores, pois segundo Walker e colaboradores ${ }^{16}$, eles podem comprometer $0 \mathrm{de}$ senvolvimento, especialmente se as pessoas não tiveram fatores de proteção que pudessem atenuar 0 impacto das adversidades.

A comparação entre os sexos quanto à ocorrência de eventos estressores não revelou diferença significativa. Tanto as meninas quanto os meninos possuem uma média de eventos aproximada.
Um estudo realizado com jovens no sul do país também não encontrou diferença significativa entre os sexos em relação à ocorrência de eventos estressores ${ }^{19}$. Embora no presente estudo não se tenha encontrado diferença entre os sexos na média de ocorrência de eventos estressores na vida de crianças e adolescentes, observou-se diferença quanto ao tipo de eventos ocorridos. Os eventos mais freqüentes relatados pelos meninos se relacionam à escola, violência e sofrer acidentes. Já os citados pelas meninas se referem a eventos envolvendo a família, como doenças, alcoolismo emortes. Tais eventos relacionados a doenças ou violência são presentes na vida de muitas crianças e podem funcionar como fatores derisco ${ }^{8,32}$. A tipificação sexual leva meninas a estarem mais envolvidas com a família e os meninos com eventos deviolência, ou seja, tais resultados podem estar relacionados às atribuições e aos papéis de cada gênero ditados pela cultura e pela sociedade ${ }^{33}$.

"Ter um familiar que bebe" foi um evento estressor freqüente citado pelas meninas do estudo. Segundo Krestan e Bepto ${ }^{34}$, quando há al coolismo entre seus membros, a família já não consegue desempenhar algumas de suas funções primordiais, que é garantir a segurança emocional e física da criança. Asmeninas deste estudo ainda mencionaram eventos pessoais, tais como: "ter problemas e dúvidas quanto às mudanças no corpo e aparência" e "ter problemas com os outros pela sua raça" como eventos estressores freqüentes. As mudanças características, tanto biológicas como psicológicas, que ocorrem no corpo durante a adolescência podem provocar estresse ${ }^{35}$. Vários estudos têm ainda sinalizado para a presença de discriminação racial nas escolas ${ }^{36,37}$. Diante disso, evidencia-se a necessidade de trabal har mais claramente essa temática nestes contextos, através de atividades que permitam a reflexão sobre as diferenças, preconceitos etolerância.

Ao analisar os grupos de eventos (família, escola e domínio pessoal) em crianças de contextos diferentes, não foi observada diferença significativa entre os sexos nos agrupamentos família e domínio pessoal. No entanto, os meninos tiveram mais eventos estressores relacionados à escola que as meninas. Os eventos estressores ocorridos no microssistema escola mais citados pelos meninos foram: "ser expulso da sala pela professora", "ser suspenso da escola" e "ser expulso da escola". Este aspecto pode ser reflexo de reais dificuldades de aprendizagem dos meninos, mas também não se pode deixar de lado as concepções da escola a este respeito eo queela espera del es. Ao mesmo tempo, é importante questionar se a escola está perceben- 
do a ocorrência dos eventos estressores vivenciados pelos meninos. Em um estudo com 243 crianças de ambos os sexos que objetivou conhecer quem são os meninos que fracassam na escola, Carvalho ${ }^{36}$ verificou queo desempenho escolar dos meninos era significativamente inferior ao das meninas. Além disso, os meninos eram mais encaminhados para atividades de reforço e rotulados pela escola como indisciplinados. É necessário levar em conta os aspectos de aprendizagem e de comportamento em suas complexasinter-relações, demaneira que se questioneo quanto a escola também tem participação nesse processo. A teoria bioecológica, ao estudar o desenvolvimento humano, destaca a importância de considerar os aspectos da pessoa, as relações significativas (processos proximais) que estabelece, os contextos nos quais convivee recebeinfluências diretas eindiretas eem que momento no ciclo vital os eventos ocorrem ${ }^{23}$. Tomando desse ângulo, as relações existentes no microssistema escolar poderão ser entendidas de maneira mais clara, uma vez que nele ocorrem diversos fenômenos que influenciam o desenvolvimento das crianças. De acordo com $\mathrm{H}$ enderson e M ilstein ${ }^{38}$, o microssistema escolar pode representar para as crianças uma alternativa de apoio, que não encontram, muitas vezes, em seu microssistema familiar.

Além dos eventos estressores relacionados à escola, "ser assaltado" e "sofrer um acidente" também foram eventos freqüentes citados pelos meninos. Tais eventos envolvem, de certa maneira, o contexto do qual fazem parte, infelizmente marcado pela violência. Segundo Heinemann e Verner ${ }^{39}$, mais de 140 mil homicídios ocorrem na América Latina por ano; este número é o dobro da média mundial. Além disso, ao selecionar indicadores como taxas de homicídios, ferimentos, assal tos e 0 tamanho do setor privado de segurança, é possível inferenciar que diversos países da América Latina apresentam sinais semelhantes a uma guerra, apesar de estar formalmente em paz. De acordo com um relatório da Organização Pan-Americana de Saúde ${ }^{40}$, os adolescentes correspondem a cerca de $20 \%$ da população do país e contribuem com $3 \%$ da mortalidade geral, com marcante predominância de mortes masculinas, sobretudo por acidentes e violências. Uma investigação ${ }^{41}$ das principais causas de óbitos de jovens brasileiros entre os anos de 1998 e 2004 apresentou uma taxa de 51,7 homicídios por 100 mil jovens, ocupando a terceira posição no ranking de 84 países em que mais jovens morrem por homicídio. Em 1980, essa taxa era detrinta jovens. N esse mesmo ranking, mas com a população total, o Brasil ocupa a quarta posição, com uma taxa de 27 homicídios por 100 mil habitantes. Os jovens vitimados em sua maioria são homens em torno de $93 \%$. Osmeninos estão, portanto, mais expostos a estas situações de violência. A morte de um amigo foi o segundo evento mais estressante para os meninos. Tal dado talvez esteja relacionado à predominância marcante de mortes masculinas, sobretudo por acidentes e violências ${ }^{40}$.

\section{O impacto dos eventos estressores}

Os eventos que foram citados como mais estressantes na amostra estudada envolvem situações de violência física, sexual e psicológica e de morte dos pais e amigos. A perda abrupta de familiares e amigos, especialmentedurante a infância eadolescência, pode trazer prejuízos sociais e emocionais para o desenvolvimento ${ }^{42}$. Tais perdas podem se configurar em fatores de risco, principalmente quando estas faziam parte de sua rede de apoio social e afetivo. A violência também está presente como evento estressor na vida dos participantes desteestudo ecom forteimpacto, deixando-os mais vulneráveis ao desenvolvimento de distúrbiosemocionais e problemas de comportamento ${ }^{43}$. 0 presente estudo não aprofundou o impacto da violência, mas verificou sua presença na vida dos jovens pesquisados e o quanto esses eventos são estressores. Todavia, para apontar que o desenvolvimento de uma criança que está sofrendo algum tipo deviolência está prejudicado, é preciso conhecer as características da vítima, os aspectos envolvidos no processo, seu momento de vida e o contexto no qual o evento violento ocorre ${ }^{8}$.

Levando em consideração contextos diferentes dedesenvolvimento, as crianças quevivem em abrigos atribuíram aos eventos "um dos pais ter fiIhos" e"afamília ter problemas com a polícia" como sendo mais estressantes do que para as crianças que moram com a família. 0 primeiro deles aponta que, muitas vezes, as crianças dos abrigos, apesar de não estarem mais morando com a família, se sentem deixadas de lado pel os pais quando estes têm outros filhos. 0 segundo evento retrata a realidade de muitas famílias que se envolvem com o tráfico de drogas e outros crimes, principalmente as que moram em bairros menos seguros. No entanto, os eventos: "não ter amigos", "envolver-se em brigas com agressão física" e "ser expulso da sala de aula pela professora" foram percebidos como mais estressantes pelas crianças e adolescentes que moram com a família. Esses eventos demonstram certo desamparo e insegurança quando associados aos eventos de violência. A pesar de 
morarem com a família, podem se configurar fatores de risco e gerarem vulnerabilidade ao desenvolvimento, podendo levar a um distúrbio físico, social e/ou emocional ${ }^{32}$. Nota-se que, apesar de estarem com suas famílias, as crianças percebem mais eventos como muito estressantes que as crianças institucionalizadas. Neste sentido, independente do microssistema no qual a criança está, ele será protetor quando as interações forem marcadas por sentimentos afetivos positivos, reciprocidade, equilíbrio de poder ${ }^{44}$. Outra possibilidade seria a de que as crianças quevivem em instituições já passaram por tantas situações difíceis que acabam lidando melhor com as adversidades que vivenciam atualmente.

Na maior parte dos eventos que apresentaram diferença significativa relacionada ao impacto entre os sexos, as meninas tiveram escores mais altos. Este resultado confirma achados de M arturano, Toller eElias ${ }^{45}$ eSilberg et al. ${ }^{46}$, que atribuem isto ao fato de as meninas estarem mais propensas a reagirem emocionalmente de maneira difusa à acumulação de eventos adversos. Além disso, diversos estudos assinalam que as meninas investem mais nos relacionamentos interpessoais, podendo assim envolver-se mais facilmente nas dificuldades das pessoas significativas que as rodeiam ${ }^{47}$.

As meninas citam como eventos de mais impacto 0 uso de drogas por familiares, talvez devido aos conflitos e insegurança que esse evento causa. Citam, ainda, a "falta de cuidados e atenção dos pais", "ficar pobre", "ter doenças graves" e "ter problemas com professores". Já os meninos atribuíram maior impacto que as meninas aos eventos "ser estuprado" e "morte de amigo". A literatura aponta que o impacto emocional, social, cognitivo e comportamental da violência sexual pode ser intenso, tanto entre os meninos como entreas meninas $^{48}$. Outro estudo realizado no sul do país não encontrou diferença significativa entre os sexos quanto ao impacto do evento de ser estuprado ${ }^{19}$. N este estudo, o estupro ocorreu com oito meninos e com catorze meninas. No entanto, os meninos, de maneira geral, apontaram o forte impacto frente a este evento. Já nas meninas, encontrou-se variabilidade nos escores de impacto. Tal dado talvez se deva ao fato de que o impacto seja maior nos meninos por falarem menos sobre esse evento. A literatura aponta dois motivos: que as pessoas duvidem da sua sexualidade e, se foi uma muIher que os abusou, évisto como engraçado enada problemático ${ }^{49}$. Diante disso, talvez sejam necessários outros estudos que explorem esse aspecto da violência sexual.
Neste estudo, foi importante investigar e levar em consideração também o impacto dos eventos estressores, porque se constatou que, apesar da ocorrência de eventos estressores, poucos são sentidos pelas crianças como totalmente estressantes. Tal resultado pode estar ligado ao fato de que essas crianças possuem recursos internos, coesão ecológica no ambiente do qual fazem parte e uma rede de apoio social e afetiva que as auxilia no enfrentamento das adversidades.

\section{Consideraçõesfinais}

Diante da alta ocorrência e impacto de eventos vivenciados pelas crianças do estudo, entende-seque elas estejam expostas e em situação de vulnerabilidade pelo que acontece ao seu redor, pela presença de violência e privação de recursos. Tal fato necessita de intervenção e reflexão, especialmente porque as soluções para tais problemáticas levantadas neste estudo não se encontram em manuais com fórmulas padronizadas ${ }^{18}$. É imprescindível que os profissionais envolvidos efetivamente se engajem no contexto ecológico no qual pretendem intervir. Devem, ainda, conhecer o processo de de senvolvimento das pessoas deste meio, suas histórias de vida, crenças e símbolos, além de conhecer as percepções que estas crianças e adolescentes têm quanto aos eventos que os circundam. Dessa forma, através deste estudo, pode-se explorar mais especificamente quais os eventos que fazem parte da realidade destes participantes, em diferentes contextos, e como são percebidos.

A gravidade e a amplitude das consequências sociais que a questão das crianças e adolescentes em situação derisco apresenta têm sido reconhecidas por diversos segmentos da sociedade. No entanto, é importante continuar investigando essa temática e como os programas políticos podem ser adequados às necessidades das populações, especialmenteporqueénecessário identificar o queé risco e para quem é.

Destaca-se a necessidade de que outros estudos investiguem a incidência dos eventos estressores pesquisados nesse estudo e, conseqüentemente, o impacto de tais eventos. Além disso, sugere-se a realização de estudos longitudinais para conhecer mais precisamente as conseqüências a longo prazo da vivência de eventos estressores, do seu acúmulo e do impacto sobre o desenvolvimento de crianças e adolescentes. 


\section{Colaboradores}

M Poletto, SH Koller eDD Dell'Aglio trabalharam na concepção teórica, elaboração e redação final do texto.

\section{Referências}

1. Masten AS, Garmezy N. Risk, vulnerability and protective factors in developmental psychopathology. In: Lahey BB, Kazdin AE, editors. Advances in clinical child psychology. Vol. 8. N ew York: Plenum Press; 1985. p. 1-52.

2. Emery RE, Forehand R. Parental divorce and children's well-being: A focus on resilience. In: Haggerty RJ, Sherrod LR, Garmezy N, Rutter MJ, editors. Stress, risk and resilience in children and adolescents: Processes, mechanisms and interventions. New York: Cambridge University Press; 1996. p. 64-99.

3. Habigzang LF, Koller SH, Azevedo GA, Xavier PM . Abuso sexual infantil e dinâmica familiar: Aspectos observados em processos jurídicos. Psicologia: Teoria e Pesquisa 2005; 21(3):341-348.

4. Oliveira L, Porciúncula LP, De M archi RB. Estratégias de coping de crianças vítimas e não vítimas de violência doméstica. Psicologia: Reflexão e Crítica 2002; 15(2):345-362.

5. Cecconello AM. Resiliência e vulnerabilidade em famílias em situação de risco [tese]. Porto Alegre (RS): Universidade Federal do Rio Grande do Sul; 2003.

6. Luthar SS. Poverty and children's adjustment. Newbury Park: Sage; 1999.

7. Garmezy N, Rutter M. Stress, coping, and development in children. New York: McGraw-Hill; 1983.

8. Koller SH, De Antoni C. Violência familiar: uma visão ecológica. In: Koller SH, organizadora. Ecologia do desenvolvimento humano: pesquisa e intervenção no Brasil. São Paulo: Casa do Psicólogo; 2004. p. 293-310.

9. Ajdukovic M, Ajdukovic D. Impact of displacement on the psychological well-being of refugee children. International Review of Psychiatry 1998; 10(3):186-195.

10. Gavranidou M. Overview of results regarding children and young people. In: Powell S, DurakovicBelko $E$, editors. The psychosocial consequences of war. Sarajevo: UNICEF B\&H; 2000. p. 127-136.

11. Wilson BJ, Gottman JM. Attention - the shuttle between emotion and cognition: Risk, resiliency and physiological bases. In: Hetherington EM, Blechman EA, editors. Stress, coping, and resiliency in children and families. New Jersey: Lawrence Erlbaum; 1996. p. 189-228.
12. Grant KE, Compas BE, Stuhlmacher AF, Thurm AE, $M$ cmahon SD, Halpert JA. Stressors and child and adolescent psychopathology: Moving from markers to mechanisms of risk. Psychological Bulletin 2003; 129(3):447-466.

13. Luthar SS. Annotation: M ethodological and conceptual issues in research on childhood resilience. Journal of Child Psychology and Psychiatric 1993; 34(4):441453.

14. Cowan PA, Cowan CP, Schulz MS. Thinking about risk and resilience in families. In: Hetherington $E M$, Blechman EA, editors. Stress, coping, and resiliency in children and families. New Jersey: Lawrence Erlbaum; 1996. p. 1-38.

15. Rutter M. Resilience in the face of adversity: Protective factors and resistance to psychiatric disorder. British Journal of Psychiatric 1985; 147(6):598-611.

16. Walker SP, Wachs TD, Gardner JM, Lozoff B, Wasserman GA, Pollitt E, Carter JA; International Child Development Steering Group. Child development: Risk factors for adverse outcomes in developing countries. The Lancet 2007; 369(556):145-157.

17. Rutter M. Psychosocial resilience and protective mechanisms. American Journal of Orthopsychiatry 1987; 57(3):316-331.

18. Koller SH, Lisboa C. Brazilian approaches to understanding and building resilience in at-risk populations. Child and Adolescent Psychiatric Clinics of $\mathrm{N}$ orth America 2007; 16(2):341-356.

19. Kristensen $\mathrm{CH}$, Leon JS, D'Incao DB, Dell'Aglio DD. Análise da freqüência e do impacto de eventos estressores em uma amostra de adolescentes. Interação em Psicologia 2004; 8(1):45-55.

20. Abreu KL, Ramos LS, Oliveira AS, Silveira A, Stoll I, Lima JS, Flores RZ, Kristensen $\mathrm{CH}$, organizadores. Avaliação do impacto de eventos de vida estressores em adolescentes da região metropolitana de Porto Alegre: desenvolvimento de uma escala. Resumo de comunicações científicas da XXXI Reunião Anual de Psicologia; 2001; Florianópolis, Brasil. Rio de Janeiro: Sociedade Brasileira de Psicologia; 2001. 
21. Garmezy N, Masten AS, Tellegen A. The study of stress and competence in children: A building block for development psychopathology. Child Development 1984; 55(1):97-111.

22. Lazarus RS, Folkman S. Stress, appraisal, and coping. New York: Springer; 1984.

23. Bronfenbrenner U. Making human beings human: Bioecological perspectives on human development. London: Sage; 2004.

24. Poletto M. Contextos ecológicos de promoção de resiliência em crianças e adolescentes em situação de vulnerabilidade [dissertação]. Porto Alegre (RS): Universidade Federal do Rio Grande do Sul; 2007.

25. Steinberg L. Adolescence. Boston: M CGraw-Hill; 1999.

26. Wagner A, Falcke D, Silveira L, M ossmann C. A comunicação em famílias com filhos adolescentes. Psicologia em Estudo 2002; 7(1):75-80.

27. Dell'Aglio DD. 0 processo de coping, institucionalização e eventos de vida em crianças e adolescentes [tese]. Porto Alegre (RS): Universidade Federal do Rio Grande do Sul; 2000.

28. Finkelhor D, Turner H, Ormrod R. Kid's stuff: The nature and impact of peer and sibling violence on younger and older children. Child Abuse $\mathrm{N}$ egl 2006; 30(12):1401-1421.

29. Bolsoni J. Interação entre irmãos: Empatia e fatores de risco e proteção [dissertação]. Porto Alegre (RS): Universidade Federal do Rio Grande do Sul; 2000.

30. Lisboa C. Comportamento agressivo, vitimização e relações de amizade de crianças em idade escolar: fatores de risco e proteção [tese]. Porto Alegre (RS): Universidade Federal do Rio Grande do Sul; 2005.

31. Poletto M, Koller SH. Contextos ecológicos: Promotores de resiliência, fatores de risco e de proteção. Estudos de Psicologia (Campinas) 2008; 25:51-66.

32. Poletto $M$, Wagner TMC, Koller SH. Resiliência e desenvolvimento infantil de crianças que cuidam de crianças: Uma visão em perspectiva. Psicologia: Teoria e Pesquisa 2004; 20(3):241-250.

33. Negreiros TC de GM, Feres-Carneiro T. Masculino e feminino na família contemporânea. Estud. pesqui. psicol 2004; 4(1):34-47.

34. Krestan J, Bepko C. Problemas de alcoolismo e o ciclo de vida familiar. In: Carter B, Mc Goldrick M, organizadores. As mudanças no ciclo da vida familiar: uma estrutura para a terapia familiar. Porto Alegre: Artes M édicas; 1995. p. 415-439.

35. Cole M, Cole SR. 0 desenvolvimento da criança e do adolescente. 4a ed. Porto Alegre: Artes M édicas; 2004.

36. Carvalho MP de. Quem são os meninos que fracassam na escola? Cadernos de Pesquisa 2004; 34(121):11-40.

37. Maggie Y. Racismo e anti-racismo: Preconceito, discriminação e os jovens estudantes nas escolas cariocas. Educação \& Sociedade 2006; 27(96):739-751.
38. Henderson N, M ilstein M M. Resiliency in schools: $M$ aking it happens for students and educators. California: Corwin; 1996.

39. Heinemann A, Verner D. Crime and violence in development: A literature review of Latin America and the Caribbean. World Bank Policy Research Working [periódico na Internet]. 2006 [acessado 2007 fev 9]; 4041: [cerca de 20 p.]. Disponível em: http://ssrn.com/ abstract $=938907$

40. O rganização Pan-Americana de Saúde. A saúde no Brasil - 2002. [site na Internet]. 2001 [acessado 2007 fev 9]: [cerca de 30 p.]. Disponível em: http://www.opas. org.br/informacao/U ploadArq/versao_fev_2003.pdf

41. Waiselfisz JJ. Mapa da violência $200 \overline{6}$ : $0 \bar{s}$ jovens do Brasil [site na Internet]. 2006 [acessado 2007 out 26]; [19p.] Disponível em : http://www.risolidaria.org.br/ docs/ficheros/200611170007_15_0.pdf

42. Loss H, Ferreira SPA, Vasconcēlos FC. Julgamento moral: Estudo comparativo entre crianças institucionalizadas e crianças de comunidade de baixa renda com relação à emergência do sentimento de culpa. Psicologia: Reflexão e Crítica 1999; 12(1):47-70.

43. De Antoni C, Koller SH. A visão da família entre as adolescentes que sofreram violência intrafamiliar. Estudos de Psicologia 2000; 5(2):347-381.

44. Bronfenbrenner U. A ecologia do desenvolvimento humano: Experimentos naturais e planejados. Porto Alegre: Artes M édicas; 1996.

45. M arturano EM, Toller GP, Santos-Elias LC. Gênero, adversidade e problemas socioemocionais associados à queixa escolar. Estudos de Psicologia (Campinas) 2005; 22(4):371-380.

46. Silberg J, Pickles A, Rutter M, Hewitt J, Simonoff E, Maes H, Carbonneau R, Murrele L, Foley D, Eaves L. The influence of genetic factors and life stress on depression among adolescent girls. Archives of General Psychiatry 1999; 56(3):225-232.

47. Rudolph KD. Gender differences in emotional responses to interpersonal stress during adolescence. Journal of Adolescent $\mathrm{H}$ ealth 2002; 30 (Supl. 1): 3-13.

48. Kristensen CH, Flores RZ, Gomes W B. Revelar ou não revelar: U ma abordagem fenomenológica do abuso sexual em meninos. In: Bruns MA de T, Holanda AF, organizadores. Psicologia e pesquisa fenomenológica: reflexões e perspectivas. São Paulo: Ômega; 2001. p. 109-142

49. Mendel M P. The male survivor: The impact of sexual abuse. London: Matthew Sage Publications; 1994.

Artigo apresentado em 05/11/2007

A provado em 26/03/2008

Versão final apresentada em 04/06/2008 